Юрий Андреевич ЛАБЫНЦЕВ 


\section{ОСТРОЖСКАЯ БИБЛИЯ 1581 Г. - ПОЛНЫЙ ПЕРВОПЕЧАТНЫЙ БИБЛЕЙСКИЙ СВОД У ВОСТОЧНЫХ СЛАВЯН ${ }^{1}$}

\section{Аннотация:}

В статье рассматривается история издания - знаменитой Острожской библии, выпущенной в 1581 г. московским и украинским первопечатником Иваном Федоровым в имении православного магната князя К.К. Острожского в г. Остроге. Острожская библия является памятником книжной культуры мирового значения и поныне остается наиболее известным и значимым старопечатным кириллическим изданием. Ее выпуск подвел итог многовекового бытования рукописных церковнославянских переводов Священного Писания. Эта книга распространена по всему миру, но больше всего ее экземпляров хранится в России и Украине.

\section{Ключевые слова:}

Острожская библия, библеистика, Иван Федоров, церковнославянский язык, славяноведение.

Abstract: Y.A. Labyntsev “The Ostrog Bible 1581: the First COMPlete Printed Bible OF THE EAST SLAVs".

The article discusses the history of the publication of the famous Ostrog Bible, published in 1581 by the Moscow and Ukrainian pioneer printer Ivan Fyodorov on the estate of the orthodox magnate Prince Konstantine in the city of Ostrog. The Ostrog Bible is a monument of book culture of world significance, it still remains the most famous and important early printed Cyrilic title. Its publication was the result of centuries of existence of the manuscript Church Slavonic translations of the Holy Scripture, Its copies are found all over the world, but the majority of its specimens are in Russia and Ukraine.

\section{Keywords:}

Ostrog Bible, biblical studies, Ivan Fyodorov, Church Slavonic language, Slavic studies.

$\mathrm{O}$ строжская библия - памятник книжной культуры мирового значения. Ее в 1581 г. издал знаменитый русский и украинский первопечатник Иван Федоров в Остроге - имении князя Константина Острожского. В своих изданиях к своему имени он прибавлял слово «Москвитин», т.е. подчеркивал, что является выходцем из Московского государства. Для выпуска библии в Остроге были созданы специальная типография и ученое сообщество, которое состояло из выдающихся книжников того времени, проделавших огромную работу по подготовке библейских рукописных текстов к печати. Благодаря их труду Острожская библия 1581 г.

\footnotetext{
1 Работа выполнена при финансовой поддержке РФФИ (грант № 18-512-76004).
} 
стала и поныне остается наиболее известным и значимым старопечатным кириллическим изданием. Оно подвело итог многовековому бытованию рукописных церковнославянских переводов Священного Писания. Его выход не только завершил длительную историю создания полного «словенского» библейского свода, но и заложил новую основу рецепции текста Священного Писания, которое являлось идейно-религиозным стержнем культурной традиции для многих европейских народов.

Инициатором подготовки и издания Острожской библии выступил магнат К. Острожский. В своем городе-имении Остроге он создал один из крупнейших православных культурно-образовательных центров Европы, известный в науке как Острожская академия (ныне она возобновлена в современной Украине в виде национального университета). Члены православного научного сообщества в Остроге поддерживали тесные связи с православным ученым миром от Московского государства на севере до греческих и славянских центров Юга и Запада Европы. Князь пригласил в Острог и Ивана Федорова, который уже успел прославиться своими трудами за пределами Московского государства на Подляшье и во Львове. После принятия решения об издании началась грандиозная редакционная работа с привлечением огромного числа библейских текстов на

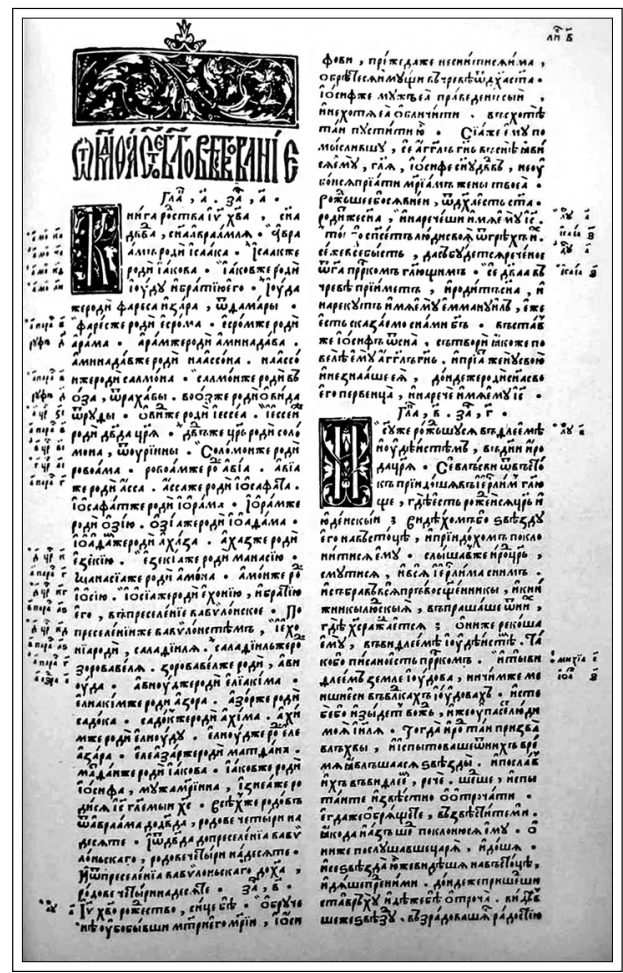

Первый лист Нового Завета в Острожской библии 15812. различных языках: греческом, латинском, чешском и польском. По собственному свидетельству князя Константина Острожского, он посылал на поиск необходимых текстов своих людей во многие европейские «пределы». Но главное книжное сокровище ему удалось обрести в Московском государстве у царя Ивана Грозного - список так называемой Геннадиевской библии 1499 г. (он был создан по распоряжению Новгородского архиепископа Геннадия в преддверии ожидаемого «конца света в 1500 г.), который и был положен в основу Острожского издания Библии: «В всех странах роду нашего языка словенскаго ниж едина обретеся съвръшена всех книгах Ветхаго Завета. Токмо от благочестива и в православии изрядно сиателна государя и великаго князя Иоанна Василиевича Московского и прочия богоизбранным мужем Михаилом Гарабурдою, писарем Великаго княз- 
ства Литовскаго, с прилежным молением испрошенную сподобихомся приати съвръшеную Вивлию». Многие обнаруженные разногласия между переводами библейских текстов устранялись в основном силами представителей острожского научного сообщества. В качестве одной из основ использовался «звод» греческой Библии, а также делались отдельные переводы с латинского текста Священного Писания.

Работа шла достаточно быстро несмотря на ее трудность и кропотливость. Непосредственное участие в подготовке рукописи Острожской библии к печати принимал и Иван Федоров, бывший превосходным текстологом и знатоком церковнославянского языка. С момента его появления деятельность печатников здесь приобрела масштабный характер. Иван Федоров значительно расширил их коллектив, подготовил необходимые запасы типографских средств и бумаги для печати столь объемного издания. Он определял стратегию издания Острожской библии, задавал темпы работы над ним, продумывал архитектонику, графическое и шрифтовое воплощение книги.

Для титульного листа Острожской библии Иван Федоров использовал рамку фронтисписа своего московского и львовского «Апостолов» 1564 и 1574 гг. На обороте титульного листа он поместил герб князя К.К. Острожского и стихи на этот герб. На следующем листе начинается предисловие от лица князя, написанное параллельно на греческом и церковнославянском языках. Затем следуют предисловие ректора Острожской академии Герасима Смотрицкого и его стихи, обращенные к читателю. На отдельном листе приводится оглавление Библии и далее идет ее текст, в конце которого помещены так называемые лекционные таблицы со «Соборником 12-тим месяцам» и послесловие Ивана Федорова на греческом и церковнославянском языках и его именная типографская марка.

Острожская библия набиралась четырьмя кириллическими и двумя греческими шрифтами. Основным их них был мелкий кириллический, напоминающий по рисунку письмо рукописей, которые создавались тогда на восточнославянских землях Речи Посполитой. Книга печаталась двумя красками: преобладающей черной и красной. В ней

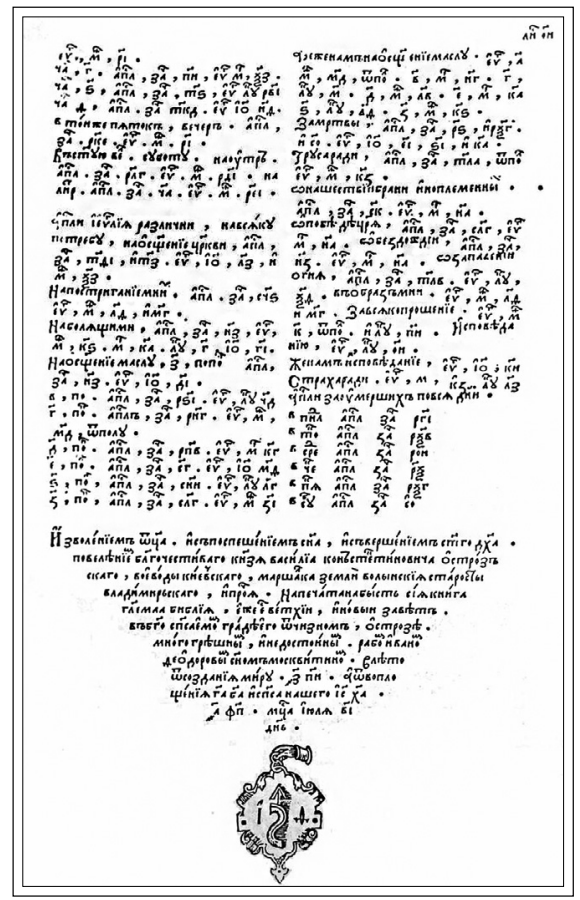

Вариант выходного листа Острожской библии 15812. с датой 12 июля 1580 г., на самом деле выпущенной в свет год спустя. 
используются инициалы, заставки, концовки, вязь и различные наборные украшения. Она насчитывает 628 листов или 1256 страниц большого формата («в лист»). На полных ее страницах помещено по 50 строк, набранных параллельно в два столбца. Сегодня известно около 400 сохранившихся экземпляров Острожской библии, но ежегодно отыскиваются ранее неучтенные. Эта книга распространена по всему миру: больше всего ее экземпляров в России и Украине, далее следуют Сербия, Польша, Великобритания, Болгария и другие страны.

В силу большой востребованности Острожская библия в 1663 г. была переиздана в Москве. Это переиздание явилось своеобразным камертоном для последующих публикаций Библии не только в России, но и за ее пределами. Для русских старообрядцев Острожская библия остается одной из главных книжных святынь и по сей день; в 1914 г. они перепечатали ее в Москве. В наше время Острожская библия переиздавалась, в том числе и с чисто научными целями. Электронные варианты воспроизведения отдельных оригинальных экземпляров Острожской библии теперь общедоступны, но сама она все еще недостаточно изучена и прежде всего филологами. Ибо, как столетие назад писал Иван Франко, она «с точки зрения на свою редакцию и свои источники <..> не дождалась еще детального исследования».

\section{ЛИТЕРАТУРА}

Ісаєвич ЯД. Першодрукар Іван Федоров і виникнення друкарства на Україні. Львів, 1983.

Лабъниев Ю., ЩавинскаяЛ. «Напечатана... Иваном Федоровым... Москвитином». M., 2007.

Немировский ЕЛ. Начало книгопечатания на Украине: Иван Федоров. М., 1974. Острожская библия: сборник статей. М., 1990.

\section{СПИСОК ИЛЛЮСТРАЦИЙ}

1. Титульный лист Острожской библии 1581 г.

2. Заглавный лист Острожской библии 1581 г.

3. Оглавление Острожской библии 1581 г.

4. Первый лист Нового Завета в Острожской библии 1581 г.

5. Вариант выходного листа Острожской библии 1581 г. с датой 12 июля 1580 г. (на самом деле она была выпущена в свет год спустя).

6. Первый лист Соборника 12 месяцев в Острожской библии. 1581 г.

7. Переплет одного из экземпляров Острожской библии. 1581 г.

8. Стихи на герб князя К.К. Острожского из Острожской библии. 1581 г.

9. Портрет князя К.К. Острожского.

10. Последняя страница послесловия Ивана Федорова на греческом и церковнославянском языках в Острожской библии. 1581 г. 